\title{
The dietary flavonoids naringenin and quercetin acutely impair glucose metabolism in rodents possibly via inhibition of hypothalamic insulin signalling
}

\author{
Christiane E. Koch ${ }^{1}$, Goutham K. Ganjam ${ }^{1}$, Juliane Steger ${ }^{1}$, Karen Legler ${ }^{1}$, Sigrid Stöhr ${ }^{1}$, \\ Daniela Schumacher ${ }^{1}$, Nigel Hoggard ${ }^{2}$, Gerhard Heldmaier ${ }^{1}$ and Alexander Tups ${ }^{1_{*}}$ \\ ${ }^{1}$ Department of Animal Physiology, Faculty of Biology, Philipps University Marburg, Karl-von-Frisch-Straße 8, \\ 35043 Marburg, Germany \\ ${ }^{2}$ Rowett Institute of Nutrition and Health, University of Aberdeen, Aberdeen AB21 9SB, UK
}

(Submitted 22 February 2011 - Final revision received 1 June 2012 - Accepted 4 June 2012 - First published online 1 August 2012)

\begin{abstract}
Secondary metabolites of herbs and spices are widely used as an alternative strategy in the therapy of various diseases. The polyphenols naringenin, quercetin and curcumin have been characterised as anti-diabetic agents. Conversely, in vitro, naringenin and quercetin are described to inhibit phosphoinositide-3-kinase (PI3K), an enzyme that is essential for the neuronal control of whole body glucose homoeostasis. Using both in vitro and in vivo experiments, we tested whether the inhibitory effect on PI3K occurs in neurons and if it might affect whole body glucose homoeostasis. Quercetin was found to inhibit basal and insulin-induced phosphorylation of Akt (Ser473), a downstream target of PI3K, in HT-22 cells, whereas naringenin and curcumin had no effect. In Djungarian hamsters (Phodopus sungorus) naringenin and quercetin $(10 \mathrm{mg} / \mathrm{kg}$ administered orally) diminished insulin-induced phosphorylation of Akt (Ser473) in the arcuate nucleus, indicating a reduction in hypothalamic PI3K activity. In agreement with this finding, glucose tolerance in naringenin-treated hamsters (oral) and mice (oral and intracerebroventricular) was reduced compared with controls. Dietary quercetin also impaired glucose tolerance, whereas curcumin was ineffective. Circulating levels of insulin and insulin-like growth factor-binding protein were not affected by the polyphenols. Oral quercetin reduced the respiratory quotient, suggesting that glucose utilisation was impaired after treatment. These data demonstrate that low doses of naringenin and quercetin acutely and potently impair glucose homoeostasis. This effect may be mediated by inhibition of hypothalamic PI3K signalling. Whether chronic impairments in glucose homoeostasis occur after longterm application remains to be identified.
\end{abstract}

Key words: Phosphoinositide-3-kinase/insulin receptor substrate signalling: Arcuate nucleus: Glucose homoeostasis

Herbs and spices have become increasingly popular for the therapy of many diseases. Secondary metabolites of herbs and spices, especially flavonoids and bioactive polyphenols, have been reported to be anti-oxidative, immunomodulating, anti-carcinogenic, anti-allergic, anti-inflammatory and anti-diabetic $^{(1)}$, exerting their biological effects via the modulation of enzymatic activity or free-radical scavenging ${ }^{(2)}$.

The polyphenols naringenin, quercetin and curcumin are common secondary metabolites. Curcumin, a curcuminoid, is used for food colouring (E100) and as a flavouring agent. It naturally occurs in the spice turmeric (Curcuma longa) and other curcuma species ${ }^{(3,4)}$. Naringenin and quercetin belong to the family of flavonoids, an important group of secondary metabolites with more than 5000 naturally occurring metabolites $^{(2)}$. Naringenin is the aglycone of naringin, which is found in citrus fruits, especially in grapefruits ${ }^{(5)}$, where it contributes to the colour and the bitter flavour. A large variety of fruits and vegetables are sources of quercetin, including black and green tea (Camellia sinensis) and onions ${ }^{(6,7)}$. All three polyphenols have been described to exhibit antidiabetic properties ${ }^{(8-11)}$. In contrast, naringenin and quercetin inhibit insulin signalling in vitro. The maintenance of whole body glucose homoeostasis is mediated via insulin stimulation of the phosphoinositide-3-kinase (PI3K) pathway, resulting in phosphorylation of the downstream target Akt (also known as protein kinase $\left.\mathrm{B}^{(12,13)}\right)$. Interestingly, naringenin and quercetin show structural similarities to the synthetic PI3K inhibitors LY294002 $2^{(14)}$ and TGX-221 (Fig. 1) and inhibit

Abbreviations: ARC, arcuate nucleus; AUC, area under the curve; ICV, intracerebroventricular; IGFBP2, insulin-like growth factor-binding protein 2; ip, intra-peritoneal; LD, long day; pAkt, phospho-Akt; PI3K, phosphoinositide-3-kinase; RQ, respiratory quotient; SD, short day.

* Corresponding author: A. Tups, fax + 49642128 28937, email alexander.tups@staff.uni-marburg.de 
(a)<smiles>O=c1cc(N2CCOCC2)oc2c(-c3ccccc3)cccc12</smiles>

PI3K inhibitor LY294002 (b)<smiles>Cc1cc(C(C)Nc2ccccc2)c2nc(N3CCOCC3)cc(=O)n2c1</smiles>

PI3K inhibitorTGX-221<smiles>O=c1c(O)c(-c2ccc(O)c(O)c2)oc2cc(O)cc(O)c12</smiles>

Quercetin (d)<smiles>O=C1CC(c2ccc(O)cc2)Oc2cc(O)cc(O)c21</smiles>

(e)<smiles>COc1cc(/C=C/C(=O)CC(=O)/C=C/c2ccc(O)c(OC)c2)ccc1O</smiles>

Curcumin

Fig. 1. Molecular structure of the phosphoinositide-3-kinase (PI3K) inhibitors (a) LY294002 and (b) TGX-221 and the polyphenols (c) quercetin, (d) naringenin and (e) curcumin. The morpholino ring of the PI3K inhibitors, which mediates the inhibitory effect on PI3K, is highlighted in light grey. The flavonoids quercetin and naringenin exhibit a related structure, the chromone moiety, marked in grey. It has been described that the chromone moiety of quercetin imitates the morpholino ring and blocks PI3K in a similar manner to the synthetic PI3K inhibitors. Curcumin offers no related structure.

PI3K in vitro ${ }^{(14,15)}$. In contrast, curcumin has been reported to activate $\mathrm{PI} 3 \mathrm{~K}^{(16)}$ and its chemical structure differs from that of naringenin and quercetin.

Our knowledge of the inhibition of PI3K by naringenin and quercetin is restricted to studies on cell lines of peripheral origin. It had been, however, well established that insulin signalling via insulin receptor substrate/PI3K in the hypothalamus is the key regulator of whole body glucose homoeostasis $^{(12,17,18)}$. Therefore, the focus of the present study is the characterisation of acute effects of these polyphenols on central insulin signalling and its contribution to whole body glucose homoeostasis in both in vitro and in vivo experiments. Using neuronal cells, we analysed whether the polyphenols affect insulin signalling. We also assessed whether flavonoids affect PI3K signalling in the brain, together with whole body glucose homoeostasis and glucose utilisation. These experiments were carried out in the Djungarian hamster (Phodopus sungorus, also known as the Siberian hamster), a well-established animal model for the studies of metabolic impairments, and in mice. The hamster reveals pronounced seasonal changes in its physiology and neuroendocrinology ${ }^{(19)}$. During a summer-like photoperiod (long day (LD)), P. sungorus increases its body weight, whereas in a winter-like photoperiod (short day (SD)), the hamster loses body weight.

\section{Material and methods}

\section{Cell culture}

Mouse hippocampal neuronal cells (HT-22) were used to investigate the effect of naringenin (CarlRoth), quercetin (Sigma-Aldrich) and curcumin (Sigma-Aldrich) on insulin signalling. Cells were maintained in Dulbecco's modified Eagle's medium supplemented with 10\% fetal bovine serum, $1 \%$ ciprofloxacin and $0.5 \%$ non-essential amino acids at an 
atmosphere of $16 \% \mathrm{O}_{2}, 79 \% \mathrm{~N}_{2}$ and $5 \% \mathrm{CO}_{2}$ (by vol.). Cells were replenished with fresh medium before treatment with polyphenols in increasing concentrations of 25, 50, 75 and $100 \mu \mathrm{M}$ for $45 \mathrm{~min}$ followed by insulin (25 nM) stimulation for another $45 \mathrm{~min}$ to measure phospho-Akt (pAkt) (Ser473). The experiment was repeated three times for the validation of the results.

\section{Protein isolation and Western blot}

Total cell lysates were isolated using Ripa lysis buffer (50 mm-Tris-Cl, $150 \mathrm{mm-NaCl,} 1 \mathrm{mm-EDTA}, 1 \% \mathrm{NP}-40$ and $0 \cdot 25 \%$ sodium deoxycholate) including phosphatase inhibitors $\left(1 \mathrm{~mm}-\mathrm{Na}_{3} \mathrm{VO}_{4}, 20 \mathrm{~mm}-\mathrm{NaF}\right)$ and a protease inhibitor tablet (Roche). The protein content in the cell lysates was estimated using a bicinchoninic acid assay kit (Thermo Fisher Scientific, Inc.). A measure of $30 \mu \mathrm{g}$ of the total protein was used for Western blot analysis. The pAkt and total Akt levels were detected using antibodies (1:1000) against pAkt (Ser473) and total Akt (Cell Signaling Technology, Inc.).

\section{Animals}

Adult female Djungarian hamsters were bred and maintained under LD conditions ( $16 \mathrm{~h}$ light $-8 \mathrm{~h}$ dark) in the animal facility of the University of Marburg. After weaning, one group remained in LD and the other group was transferred to SD conditions with a light-dark cycle of $8-16$ h. All hamsters were kept individually at an ambient temperature of $23^{\circ} \mathrm{C}$ and were 2-4 months old at the time of the experiments. SD hamsters were kept under SD conditions for 2 months until they were fully adapted to the short photoperiod.

Female C57BL/6JRj-mice ( 8 week old) were purchased from Janvier. They were housed individually with a light-dark cycle of $12-12 \mathrm{~h}$ and at a room temperature of $26^{\circ} \mathrm{C}$.

All animals had access to food and water ad libitum, unless otherwise stated. To determine the respiratory quotient (RQ), hamsters were food restricted $8 \mathrm{~h}$ before quercetin application. In all other experiments, hamsters and mice were food deprived for $16 \mathrm{~h}$ prior to the experiments.

All procedures were in accordance with the Guidelines of the German Council of Animal Care.

\section{Polyphenol administration}

Naringenin, quercetin and curcumin were dissolved in $10 \%$ ethanol-water and were administered orally. For the oral application, animals were anaesthetised with ketamine (hamster: $70 \mathrm{mg} / \mathrm{kg}$ body weight; mouse: $40 \mathrm{mg} / \mathrm{kg}$ body weight; Essex Tierarznei Niederlassung), an anaesthetic that does not affect glucose metabolism ${ }^{(20)}$. Hamsters employed in the metabolic measurements were anaesthetised for a maximum of $30 \mathrm{~s}$ with $4 \%$ isoflurane (CP-Pharma Handelsgesellschaft) for oral application. Intracerebroventricular (ICV) injection of naringenin $(2 \mu \mathrm{l} ; 5 \mathrm{nmol}$ in $5 \%$ dimethyl sulphoxide/artificial cerebrospinal fluid) in mice via stereotaxically implanted cannulae ${ }^{(21)}$ was performed without any anaesthesia.

\section{Anaesthetics and their influence on basal blood glucose} concentration

To exclude the possibility that the use of anaesthetics might distort the effects of polyphenols on glucose homoeostasis, we tested whether ketamine or very brief isoflurane (maximal 30s) anaesthesia alters basal blood glucose levels in hamsters. LD female hamsters were fasted for $16 \mathrm{~h}$ and divided into three groups. One group was anaesthetised with ketamine $(70 \mathrm{mg} / \mathrm{kg}$ body weight; $n$ 7), the second group was briefly anaesthetised with isoflurane ( $4 \%$ for maximum of $30 \mathrm{~s} ; n$ ) and the third group was decapitated without anaesthesia ( $n$ 9); blood glucose concentrations were detected by using a commercially available glucometer (Accu-Check Performa; Roche). To determine the blood glucose levels of anaesthetised hamsters, the vena sublingualis was punctured and the glucose concentration was measured.

\section{Insulin-induced phosphorylation of Akt (Ser473)}

PI3K activity was analysed by detecting the phosphorylation of Akt (Ser473) after polyphenol treatment and insulin injection, as described previously ${ }^{(21,22)}$. pAkt (Ser473) immunoreactive cells in the arcuate nucleus (ARC) were counted by two investigators blind to the treatments. The total insulin-induced activation of PI3K without polyphenol pretreatment is represented as $100 \%$ pAkt (Ser473) counted cells; all other values are represented relative to this value in percentage.

\section{Glucose tolerance tests after polyphenol treatment}

The effect of oral naringenin on peripheral glucose tolerance was analysed in LD and SD hamsters (LD: $n$ 3-8 hamsters/group; SD: $n 5$ hamsters/group). In mice, the effect of oral ( $n 8 \mathrm{mice} /$ group) as well as central ( $n 3$ mice/group) naringenin was assessed. The oral effect of curcumin and quercetin on glucose tolerance was determined in LD hamsters only ( $n$ 16-20 hamsters/group).

Fasted (16h) animals were treated orally or centrally with either polyphenol (oral: $10 \mathrm{mg} / \mathrm{kg}$ body weight; ICV: $5 \mathrm{nmol} / \mathrm{mouse}$ ) or vehicle (oral: 10\% ethanol-water; ICV: $5 \%$ dimethyl sulphoxide/artificial cerebrospinal fluid). At $15 \mathrm{~min}$ after polyphenol treatment, the animals received an intraperitoneal (ip) glucose injection (hamster: $2 \mathrm{~g} / \mathrm{kg}$ body weight; mouse: $1 \mathrm{~g} / \mathrm{kg}$ body weight).

To determine blood glucose concentrations, the vena sublingualis (hamster) or the vena facialis (mouse) was punctured and the glucose concentration was detected ${ }^{(21)}$. Due to restricted blood withdrawal from the vena sublingualis, hamsters were anaesthetised with ketamine during the entire glucose tolerance test. Mice were anaesthetised (ketamine) for oral naringenin application only.

For central application, steel cannulae were stereotaxically implanted into the lateral cerebral ventricle of mice. The details of the procedure have been described previously $^{(21)}$. 
Insulin and insulin-like growth factor-binding protein 2 ELISA

To test potential effects of the polyphenols on circulating levels of insulin and insulin-like growth factor-binding protein 2 (IGFBP2), we performed an ELISA. To detect the insulin concentration in blood serum, food-restricted hamsters were pre-treated orally with naringenin, quercetin, curcumin or vehicle ( $n 6$ hamsters/group). At $15 \mathrm{~min}$ after polyphenol treatment, insulin production and secretion were stimulated via an ip glucose injection ( $2 \mathrm{~g} / \mathrm{kg}$ body weight). The vena sublingualis was punctured $30 \mathrm{~min}$ later and blood was collected using uncoated capillary tubes and prepared for insulin measurement. To detect serum IGFBP2 levels, fasted hamsters were treated orally with the polyphenols or vehicle $(10 \%$ ethanol-water). At $60 \mathrm{~min}$ after treatment, blood was collected and stored on ice for approximately $1.5 \mathrm{~h}$ and then centrifuged for $20 \mathrm{~min}$ at $3500 \mathrm{rpm}$ at $4^{\circ} \mathrm{C}$. The supernatant containing serum was used to measure the serum insulin (Linco Research) and serum IGFBP2 concentrations (Alpco) by ELISA.

\section{Metabolic measurement}

To measure metabolism, $\mathrm{VCO}_{2}$ and $\mathrm{VO}_{2}$ were measured in hamsters in metabolism cages (approximately 1.8 litres; $17 \mathrm{~cm} \times 11 \mathrm{~cm} \times 12 \mathrm{~cm}$ ). Measurements were taken in the morning at a constant ambient temperature of $23^{\circ} \mathrm{C}$. The air flow in the cage was adjusted to approximately $45 \mathrm{l} / \mathrm{h}$ and continuously monitored. The procedure has been described in detail previously ${ }^{(23)}$.

Individually caged hamsters had no access to food, resulting in a slow decrease in RQ. After approximately $8 \mathrm{~h}$, the RQ had gone down to approximately 0.85; the hamsters were taken out of the chamber and anaesthetised briefly using isoflurane. Quercetin $(10 \mathrm{mg} / \mathrm{kg}$ body weight) or vehicle $(10 \%$ ethanol-water) was administered orally; $15 \mathrm{~min}$ later, hamsters that recovered from anaesthesia received an ip injection of glucose $(2 \mathrm{~g} / \mathrm{kg}$ body weight) or vehicle $(\mathrm{NaCl})$ and were retransferred to the climate chamber. The RQ was measured for the next $90 \mathrm{~min}$ ( $n 10$ hamsters/group). For consistent results, only hamsters with an RQ of approximately 0.85 were used in the experiment.

\section{Body weight gain, food intake and water consumption} after polyphenol administration

To analyse the effect of the polyphenols on energy metabolism, LD hamsters were food restricted for $24 \mathrm{~h}$. At $1 \mathrm{~h}$ before the onset of the dark phase, hamsters were orally treated with quercetin, naringenin, curcumin $(10 \mathrm{mg} / \mathrm{kg}$; $n$ 9/group) or vehicle ( $10 \%$ ethanol-water; $n$ 8). Body weight changes, food intake and water consumption were measured 4 and $24 \mathrm{~h}$ after oral polyphenol administration.

\section{Statistics}

In vitro data were analysed by two-way ANOVA followed by the Holm-Sidak comparison test, using SigmaStat statistical software (Jandel).
Animal data were analysed by one-way ANOVA followed by the Holm-Sidak comparison test (SigmaStat), as appropriate. Where data failed equal variance or normality tests, they were analysed by one-way ANOVA followed by Dunn's multiple comparison test. The hamster naringenin glucose tolerance test was analysed by two-way ANOVA followed by the Holm-Sidak comparison test. Results are presented as means with their standard errors and $P<0.05$ was considered significant.

\section{Results}

Effect of polyphenols on Ser473 phosphorylation of Akt in HT-22 cells

Mouse hippocampal neuronal cells (HT-22) were treated with increasing concentrations of naringenin, quercetin and curcumin to investigate the effect of these compounds on phosphorylation of Akt (Ser473). Cells treated with $25 \mathrm{~nm}$-insulin for $45 \mathrm{~min}$ significantly increased the amount of pAkt (Ser473) protein by greater than 2 -fold (vehicle $v$. insulin; $P<0 \cdot 001)$. Naringenin-treated cells failed to inhibit both basal as well as insulin-stimulated phosphorylation of Akt (Ser473) at all concentrations (Fig. 2(a)). Quercetin potently inhibited basal phosphorylation of Akt at all four concentrations (vehicle/vehicle $v$. quercetin/vehicle; $P=0 \cdot 02$ ). Insulin-stimulated phosphorylation was inhibited by quercetin (vehicle/insulin $v$. quercetin/insulin; $P=0 \cdot 009$ ), reducing pAkt to an almost basal level (Fig. 2(b)). As with naringenin, curcumin treatment failed to inhibit both basal and insulinstimulated phosphorylation of Akt (Ser473) at lower concentrations. However, pAkt (Ser473) levels were undetectable when curcumin was given at a high concentration of $100 \mu \mathrm{M}$ (Fig. 2(c)). Polyphenol treatment only affected the phosphorylation of Akt, while total Akt was not influenced by polyphenols, indicating viability of the cells.

\section{Effect of polyphenols on insulin-induced phosphorylation of Akt (Ser473) in the arcuate nucleus}

To investigate whether these polyphenols show effects on PI3K in vivo, we characterised the acute effect of polyphenol treatment on hypothalamic PI3K signalling in hamsters by measuring pAkt (Ser473) immunoreactive cells in the hypothalamus. Hamsters were treated orally with naringenin, quercetin, curcumin or vehicle followed by an ip insulin injection $15 \mathrm{~min}$ later. After $15 \mathrm{~min}$, the hamsters were killed. We recently have established that insulin induces a robust increase in the number of pAkt (Ser473) immunoreactive cells in the $\mathrm{ARC}^{(21,22)}$. Thus, the number of cells counted in animals treated with insulin alone was considered to represent maximal stimulation, i.e. $100 \%$ ( $n 10$ hamsters). Oral pre-treatment with the flavonoids naringenin ( $n 8$ hamsters) and quercetin ( $n 6$ hamsters) reduced the number of insulin-induced pAkt (Ser473) cells in the ARC by approximately 20\% (Fig. 3(a, b)), suggesting an inhibition of insulin stimulation (vehicle $v$. naringenin; $P=0.016$; vehicle $v$. quercetin; $P=0.049$ ). In contrast, curcumin pre-treatment did not alter the number 

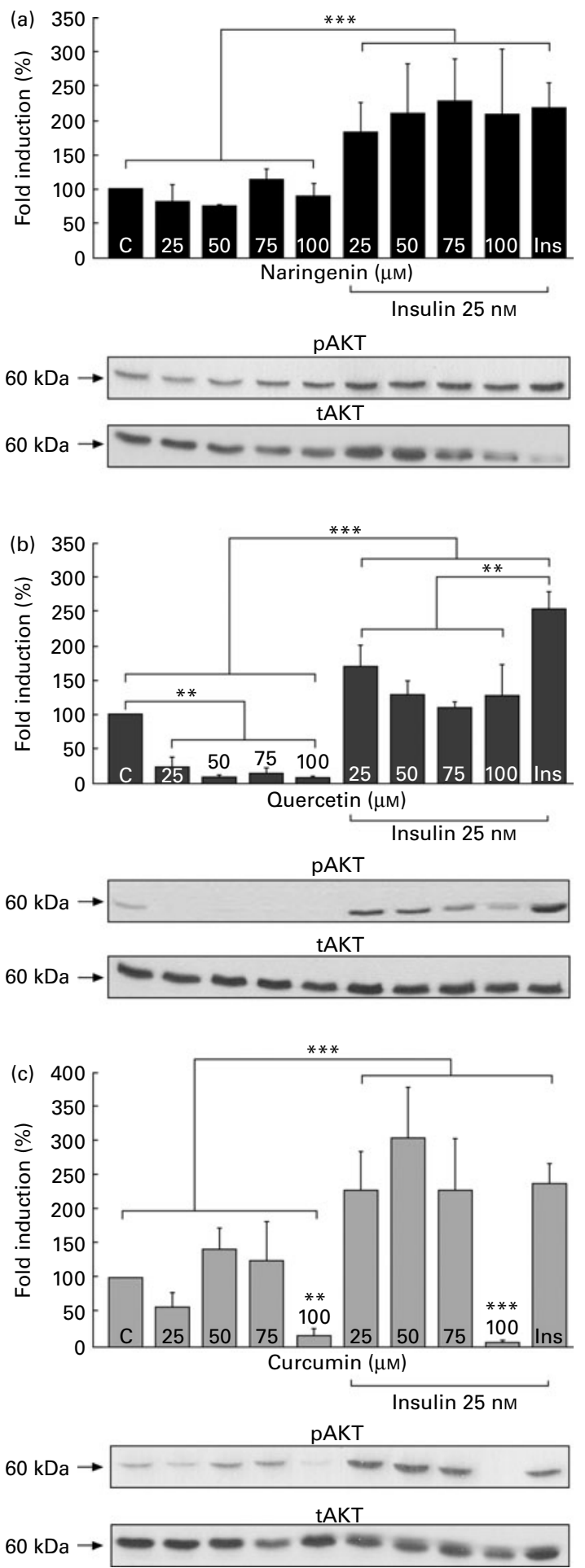

Fig. 2. Quercetin significantly reduced insulin (Ins)-induced phospho-Akt (pAkt) (Ser473) in HT-22 cells. Mouse hippocampal cells (HT-22) were treated with vehicle or the respective polyphenol in increasing concentrations from 25 to $100 \mu \mathrm{M}$. (a) Naringenin; (b) quercetin; (c) curcumin with or without Ins $(25 \mathrm{mM})$ stimulation. The ratio between pAkt and total Akt was semiquantitatively assessed by immunoblotting using a phosphor-specific antibody for pAkt. One of three quantified Western blot membranes representing pAkt (Ser473) and total Akt protein is shown below the bar charts. C, control. Values are means with their standard errors. Mean values were significantly different: ${ }^{\star \star} P<0.01,{ }^{\star \star *} P<0.001$. of insulin-induced pAkt immunoreactive cells in the ARC (Fig. 3(a, b); $n 8$ hamsters). In brain regions outside the hypothalamus, pAkt immunoreactive cells were not detectable (data not shown).

\section{Effect of polyphenols on peripheral glucose tolerance}

Having established that naringenin and quercetin inhibit neuronal insulin signalling, we investigated whether naringenin and quercetin could also affect glucose homoeostasis in the animals.

Due to the limitation of blood withdrawal from vena sublingualis in hamsters under anaesthesia, we first tested whether ketamine anaesthesia per se affected basal blood glucose levels. Basal blood glucose levels of decapitated non-anaesthetised and ketamine anaesthetised hamsters were not significantly different. They were in a range of $700-750 \mathrm{mg} / \mathrm{l}$ (hamsters without anaesthesia $=752 \quad(\mathrm{sEM}$ 4.3) $\mathrm{mg} / \mathrm{l}(n$ 7), anaesthetised hamsters $=704(\mathrm{sem} 8.5) \mathrm{mg} / \mathrm{l}$ $(n 9)$ ), confirming that ketamine anaesthesia has no effect on glucose levels. This is consistent with other rodent species ${ }^{(20)}$.

Firstly, we analysed the acute effect of an oral naringenin application on peripheral glucose tolerance in LD ( $n$ 3-8 hamsters/group) and SD acclimated hamsters ( $n$ 5-8 hamsters/group). Independent of the photoperiod, naringenin impaired glucose tolerance profoundly (Fig. 4(a)). The area under the curve (AUC) of naringenin-treated animals was significantly increased (naringenin $v$. vehicle, $P<0.001$; LD naringenin $v$. vehicle, $P=0.002$; SD naringenin $v$. vehicle, $P=0 \cdot 016$ ). No interaction between photoperiod and treatment occurred. To exclude the possibility that the observed phenomenon is restricted to hamsters only, we also performed an intra-peritoneal glucose tolerance test in $\mathrm{C} 57 \mathrm{BL} / 6 \mathrm{JRj}$ mice. As in the hamster, orally administered naringenin impaired whole body glucose tolerance in mice ( $n 8$ mice/group, Fig. 4(b)) with a significant increase in AUC after this treatment (naringenin $v$. vehicle, $P=0 \cdot 01$ ).

To ascertain whether this impairment of whole body glucose homoeostasis by flavonoid treatment is mediated via inhibition of PI3K in the brain, we administered naringenin ICV ( $n 3$ mice/group). The flavonoid was as effective in impairing whole body glucose tolerance (naringenin $v$. vehicle; $P=0.004$ ) as when given peripherally (Fig. 4(c)). As naringenin impaired glucose homoeostasis robustly and independently of photoperiod or species, all subsequent experiments were carried out in LD hamsters only. In LD hamsters, quercetin also impaired glucose tolerance at a similar magnitude as naringenin ( $n$ 16-20 hamsters/group). The AUC was significantly increased compared with vehicletreated animals (Fig. 4(d); quercetin $v$. vehicle, $P<0.001$ ). However, consistent with the data shown above, curcumin ( $n$ 16 hamsters) had no effect on peripheral glucose tolerance (Fig. 4(d)).

\section{Effect of polyphenol treatment on blood serum parameters}

In the present experiment, we investigated whether polyphenols caused any alteration in circulating levels of, 
(a)

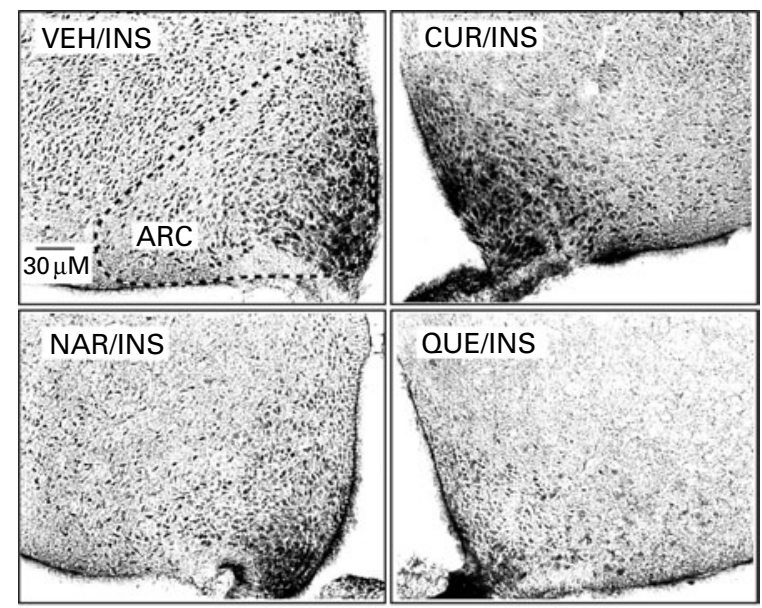

(b)

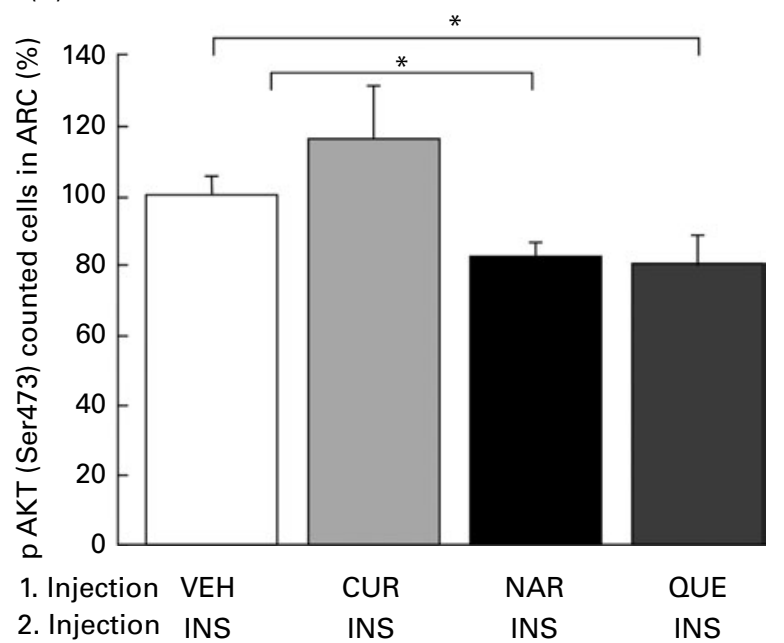

Fig. 3. Naringenin (NAR) and quercetin (QUE) decreased insulin (INS)induced phospho-Akt (pAkt) (Ser473) in the arcuate nucleus (ARC) of Djungarian hamsters. Immunohistochemistry for pAkt (Ser473) was performed on brain sections of Djungarian hamsters. Long day hamsters received vehicle (VEH), NAR, QUE or curcumin (CUR) $(10 \mathrm{mg} / \mathrm{kg}$ body weight administered orally) $30 \mathrm{~min}$ before intra-peritoneal INS injection. At $15 \mathrm{~min}$ after INS injection, hamsters were transcardially perfused. (a) Representative images showing pAkt (Ser473) immunoreactivity in the ARC of Djungarian hamsters. (b) The bar graph shows the number of immunoreactive pAkt (Ser473) cells in the ARC ( $n 6-10$ hamsters/group). Mean value of the control was defined as $100 \%$, and all other values are expressed in percentage to this value. Values are means with their standard errors. Mean values were significantly different: ${ }^{*} P<0.05$.

e.g. serum insulin and serum IGFBP2. The latter has recently been shown to contribute to the insulin-sensitising action of central leptin ${ }^{(24)}$. Hamsters were treated orally with polyphenols prior to a glucose tolerance test $(2 \mathrm{~g} / \mathrm{kg}$ body weight). The glucose-stimulated insulin secretion after all polyphenol pre-treatments was similar to the vehicle-injected group ( $n 6$ hamsters/group), with insulin concentrations in the range of $3-4 \mathrm{ng} / \mathrm{ml}$ (Fig. 5(a)). Also, the polyphenols had no effect on IGFBP2 concentration, which was in the range of approximately $120-130 \mathrm{ng} / \mathrm{ml}$ (Fig. 5(b); $n 6$ hamsters/group) for all animals.

\section{Effect of quercetin on glucose metabolism}

At the doses tested, quercetin was the most potent polyphenol at impairing glucose tolerance. Therefore, we investigated whether quercetin affects glucose metabolism in hamsters. We analysed whether dietary quercetin influences the RQ as a marker for metabolic adjustments. As in previous experiments $^{(25)}$, a typical RQ of approximately 0.9 was seen in hamsters, which decreased during the period of food deprivation to approximately 0.85 . Increased glucose utilisation, as reflected in an increase in the RQ, was typically achieved after an ip glucose injection ( $2 \mathrm{~g} / \mathrm{kg}$ body weight). Quercetin pre-treatment $15 \mathrm{~min}$ before glucose application reduced glucose utilisation, shown by an alleviated glucose-stimulated increase of the RQ in quercetin pre-treated animals ( $n$ 10 hamsters/group; Fig. 6(a)). The maximal rise in the $\mathrm{RQ}$ was decreased in quercetin pre-treated hamsters compared with vehicle pre-treated hamsters, while the oxygen consumption was identical in both groups (Fig. 6(d)). The glucose-induced rise in RQ, defined as $\Delta \mathrm{RQ}$, was significantly reduced after quercetin pre-treatment (Fig. 6(b); $P=0 \cdot 006$ ). Additionally, the incremental AUC of quercetin pre-treated hamsters was decreased (Fig. 6(c); quercetin $v$. vehicle, $P=0 \cdot 03)$. For evaluation of incremental AUC, the time interval from 0 (quercetin and glucose application) up to 60 min was used (light grey highlighted in Fig. 6(a))

The very brief isoflurane anaesthesia (maximal 30s), which was necessary for oral application of quercetin, had no effect on basal blood glucose concentration. Basal blood glucose concentrations of anaesthetised and non-anaesthetised hamsters were comparable and in a range of $710-750 \mathrm{mg} / \mathrm{l}$ (non-anaesthetised hamsters $=752 \quad(\operatorname{sem} 4 \cdot 3) \mathrm{mg} / \mathrm{l} \quad(n \quad 7)$; anaesthetised hamsters $=712(\operatorname{sem} 2 \cdot 5) \mathrm{mg} / \mathrm{l}(n$ 5) $)$.

\section{Body weight gain, food intake and water consumption after polyphenol administration}

We next analysed whether polyphenols modulate energy metabolism of LD hamsters. Body weight gain of hamsters treated with quercetin or naringenin was significant at 4 and $24 \mathrm{~h}$ after administration compared with controls (quercetin $v$. vehicle, $P=0.0103$; naringenin $v$. vehicle, $P=0 \cdot 021$; Fig. $7(\mathrm{a})$; $n 8-9$ /group). Food intake of quercetin- and naringenin-treated hamsters was increased $24 \mathrm{~h}$ after flavonoid administration (quercetin $v$. vehicle, $P=0 \cdot 01$; naringenin $v$. vehicle, $P=0 \cdot 024$; Fig. 7(b); $n 8-9 /$ group). Consistent with the above experiments, curcumin also did not affect energy metabolism of hamsters. Body weight gain and food intake of curcumintreated hamsters was comparable with controls (Fig. 7(a, b); $n$ 8-9/group). Water consumption was not influenced by treatment with any polyphenol (Fig. 7(c); $n$ 8-9/group).

\section{Discussion}

Whether the polyphenols quercetin, naringenin and curcumin exert anti- or pro-diabetic properties has not been well characterised. According to previous in vitro and in vivo experiments, their actions on glucose metabolism remain 

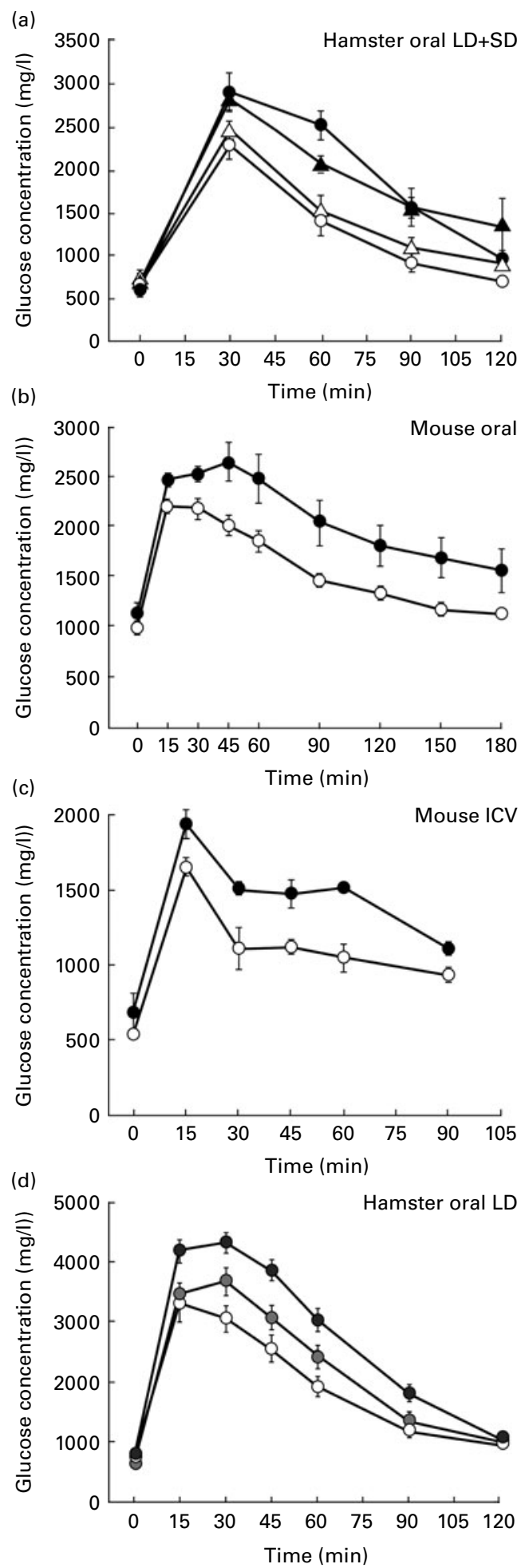
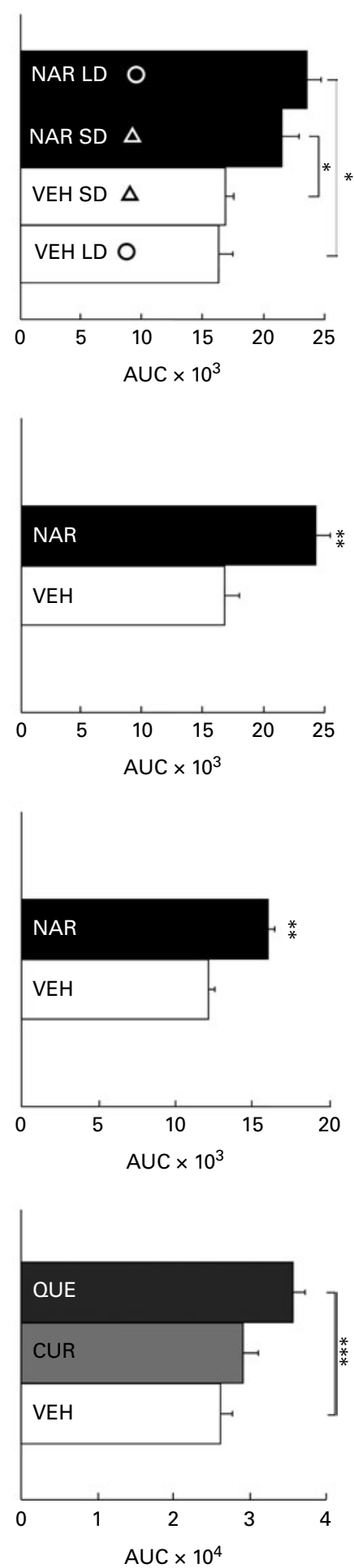

Fig. 4. Naringenin (NAR) and quercetin (QUE) significantly impaired the whole body glucose tolerance of Djungarian hamsters and mice. (a) Glucose clearance during an intra-peritoneal (ip) glucose tolerance test (ipGTT) and the corresponding area under the curve (AUC) of Djungarian hamsters treated orally with NAR $(10 \mathrm{mg} / \mathrm{kg}$ body weight; long day $(\mathrm{LD}, \bullet)=$ three hamsters; short day (SD $\mathbf{\Delta})=$ five hamsters) or vehicle $(\mathrm{VEH} ; 10 \%$ ethanol-water; LD $(\mathrm{O})=$ eight hamsters; SD $(\Delta)=$ five hamsters) $15 \mathrm{~min}$ prior to an ip glucose injection ( $2 \mathrm{~g} / \mathrm{kg}$ body weight). (b) Glucose clearance during an ipGTT and the corresponding AUC of 8-week-old mice ( $n 8$ mice/group) pre-treated orally with NAR (10 mg/kg body weight) or VEH (10\% ethanol-water) $15 \mathrm{~min}$ prior to an ip glucose injection (1 g/kg body weight). (c) Glucose clearance during an ipGTT and the corresponding AUC of 8-week-old mice ( $n 3$ mice/group) injected centrally with either NAR ( 5 nmol in $5 \%$ dimethyl sulphoxide (DMSO)/artificial cerebrospinal fluid (aCSF)) or VEH (5\% DMSO/aCSF) 15 min prior to an ip glucose injection (1 $\mathrm{g} / \mathrm{kg}$ body weight). (d) Glucose clearance during an ipGTT and the corresponding AUC of Djungarian hamsters (LD; $n$ 16-20 hamsters/group) treated orally with QUE, curcumin (CUR) (each $10 \mathrm{mg} / \mathrm{kg}$ body weight) or VEH (10\% ethanol-water) $15 \mathrm{~min}$ prior to an ip glucose injection ( $2 \mathrm{~g} / \mathrm{kg}$ body weight). ICV, intracerebroventricular. Values are means with their standard errors. Mean values were significantly different: ${ }^{\star} P<0.05,{ }^{\star \star} P<0.01,{ }^{\star \star \star} P<0.001$. 

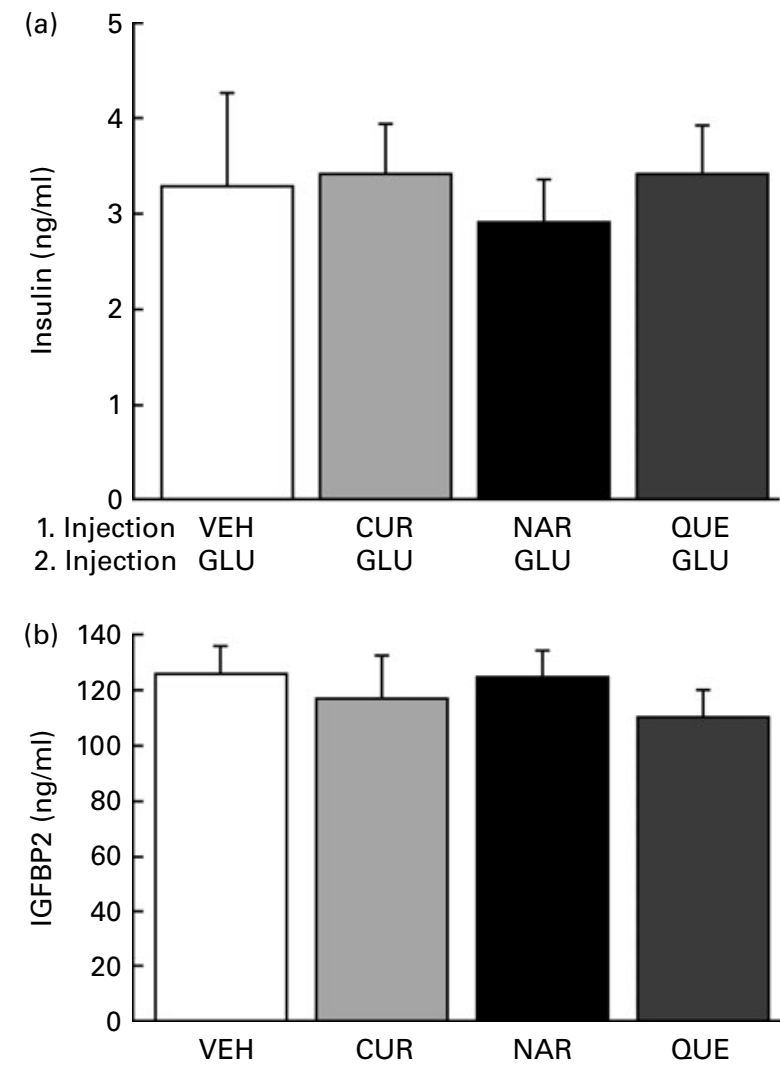

Fig. 5. Polyphenol treatment did not affect circulating levels of insulin and insulin-like growth factor-binding protein 2 (IGFBP2) in Djungarian hamsters. (a) Effect of polyphenols on glucose (GLU)-stimulated serum insulin concentrations of Djungarian hamsters (long day (LD); $n 6$ hamsters/group). Hamster received naringenin (NAR), quercetin (QUE), curcumin (CUR) (10 mg/kg body weight) or vehicle (VEH) (10\% ethanol-water) orally, $15 \mathrm{~min}$ prior to an intra-peritoneal GLU injection ( $2 \mathrm{mg} / \mathrm{kg}$ body weight). At $30 \mathrm{~min}$ after GLU stimulation, blood was taken from the vena sublingualis. (b) Serum IGFBP2 concentration at $60 \mathrm{~min}$ after oral application of NAR, QUE, CUR ( $10 \mathrm{mg} / \mathrm{kg}$ body weight; $n 6$ hamsters/group) or VEH (10\% ethanol-water; $n 6$ hamsters/group). Values are means with their standard errors.

controversial. It has been shown that naringenin and quercetin inhibited insulin signalling via the PI3K pathway in vitro ${ }^{(14,15)}$. Additionally, both polyphenols inhibit glucose uptake in breast cancer cells ${ }^{(26)}$ and in adipocytes ${ }^{(27,28)}$ via blockade of GLUT4 translocation, which is regulated by $\mathrm{PI} 3 \mathrm{~K}^{(29-31)}$. These data obtained from in vitro experiments strongly suggest that these two polyphenols might also impair glucose homoeostasis in vivo. Some in vivo experiments, however, suggest that naringenin and quercetin exhibit anti-diabetic properties. Indeed long-term treatment with quercetin and naringenin has been shown to significantly reduce blood glucose levels in a mouse model of type 1 diabetes ${ }^{(9)}$. Other studies described that both polyphenols significantly improved diet-induced insulin resistance triggered by high fructose or high fat feeding in mice and rats ${ }^{(8,32,33)}$. As for naringenin and quercetin, curcumin has not been consistently described as having anti- or pro-diabetic actions. In one study, it inhibited insulin-induced GLUT 4 translocation and therefore glucose uptake in 3T3-L1 adipocytes. In another study, curcumin was described to inhibit the phosphorylation of Akt in human prostate cancer and renal carcinoma cells ${ }^{(34,35)}$. In contrast, curcumin increased the phosphorylation of Akt in melanoma cell lines ${ }^{(36)}$. Moreover, some in vivo studies defined curcumin as an anti-diabetic agent. It improved muscle insulin resistance in a diabetic rat model $^{(10)}$ and prevented the increase in blood glucose during the onset of diabetes ${ }^{(37)}$.

In the present study, we assessed whether these polyphenols are able to impair insulin signalling in a neuronal cell line and whole body glucose homoeostasis of the Djungarian hamster and mice. Notably, no effect of photoperiod on glucose homoeostasis was observed. Therefore, all experiments scrutinising the mechanism of how the flavonoids act on glucose metabolism were carried out in LD hamsters and in mice. Quercetin, which was described as a kinase inhibitor ${ }^{(14)}$, consistently reduced insulin-induced activation of the PI3K pathway both in vitro and in vivo. Naringenin was equally effective in vivo, reducing the number of ARC pAkt immunoreactive cells after insulin stimulation to a similar level. Curcumin, however, was only able to inhibit insulin-induced activation of Akt in the neuronal cell line in a high dose. These discrepancies between in vitro and in vivo effects of the polyphenols may be explained by the substantial differences between cell culture and whole animal experiments. Circulating hormones may be required to enable naringenin to exert its full PI3K-inhibiting capacity. Also, insulin signalling in the hippocampus and in the ARC is likely to be similar as insulin and leptin receptors are expressed and PI3K is active in both regions ${ }^{(38-42)}$. Leptin signalling via the PI3K pathway in the ARC and hippocampus leads to a similar behavioural response, e.g. in food intake, further substantiating the idea that signal transduction mechanisms are likely to be similar in both regions ${ }^{(43,44)}$. Methodological differences in performing immunohistochemistry in the ARC and measuring pAkt by immunoblotting in hippocampal cells might also contribute to this discrepancy. A further aspect is the bioavailability and the metabolism of the polyphenols in vivo. While curcumin inhibited insulin-stimulated pAkt in vitro, but not in vivo, this may be due to the low bioavailability of curcumin ${ }^{(45,46)}$ Naringenin, absorbed in the small intestine, is hydrolysed from naringin and only the aglycone naringenin is detectable in the circulation ${ }^{(47)}$. It cannot be ruled out that secondary metabolites of naringenin, e.g. glucurono and sulfoconjugated derivatives, are bioactive in vivo and contribute to the inhibition of insulin signalling. However, the likelihood that these derivates enter tissue cells is low due to their increased polarity that reduces their ability to cross the lipid cell membrane.

The ability of naringenin to impair glucose tolerance was of similar magnitude, whether the flavonoid was given ICV or orally. This together with the finding that naringenin reduced the number of pAkt immunoreactive cells after insulin stimulation suggests that the effect to impair glucose tolerance is mediated centrally. Dietary administration of naringenin to rats resulted in high detectable levels in the plasma, reaching concentrations of $35 \mu \mathrm{m}^{(47)}$. It has been well described that naringenin and quercetin, both lipophilic molecules, can cross the blood-brain barrier in an in situ model ${ }^{(48-50)}$. 

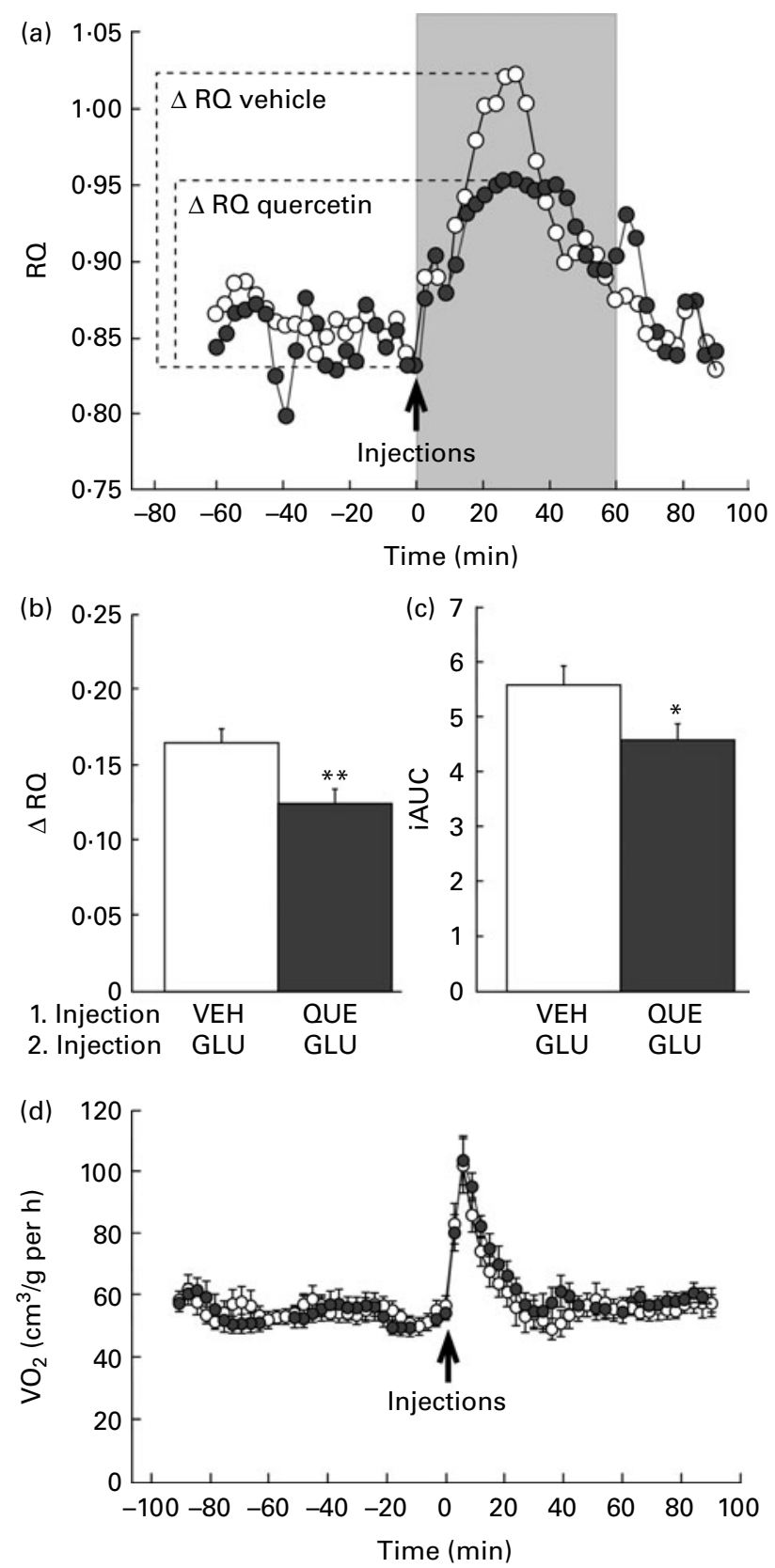

Fig. 6. Quercetin (QUE) acutely impaired glucose (GLU) utilisation in Djungarian hamsters. (a) Representative $R Q$ of two adult female long day hamsters treated orally with either QUE (10 mg/kg body weight; 0 ) or vehicle (VEH; $10 \%$ ethanol-water; O) $15 \mathrm{~min}$ prior to an intra-peritoneal (ip) GLU injection ( $2 \mathrm{mg} / \mathrm{kg}$ body weight). Injection phase is marked with an arrow, time period for the incremental area under the curve (AUC) calculation (shown in Fig. 5(b)) is highlighted in light grey and calculation of $\triangle R Q$ (shown in Fig. 5(c)) is represented by dotted lines. (b) Maximal increase of the RQ $(\triangle \mathrm{RQ}$ ) of these hamsters ( $n 10$ hamsters/group) after QUE or VEH pre-treatment. (c) iAUC of hamsters ( $n 10$ hamsters/group) treated orally with QUE (10 mg/kg body weight) or VEH (10\% ethanol-water) $15 \mathrm{~min}$ prior to an ip GLU injection (2 mg/kg body weight). (d) Oxygen consumption of Djungarian hamsters ( $n 10$ hamsters/group) treated orally with QUE (10 mg/kg body weight; O) or VEH (10\% ethanol-water; O) $15 \mathrm{~min}$ prior to an ip GLU injection ( $2 \mathrm{mg} / \mathrm{kg}$ body weight). Injection phase is marked with an arrow. Values are means with their standard errors. Mean values were significantly different: ${ }^{\star} P<0.05,{ }^{\star \star} P<0.01$.
Furthermore, it has been shown that, specifically in the brain, a high retention of the aglycone naringenin and not its metabolites occurred even as long as $18 \mathrm{~h}$ after a naringeninenriched meal ${ }^{(51)}$. Also, dietary naringenin inhibits the proliferation of cerebrally implanted glioma cells in rats ${ }^{(52)}$, suggesting that the molecule is bioactive in the brain tissue.

Quercetin was also able to impair glucose tolerance in hamsters. Furthermore, it reduced glucose utilisation measured by a reduction in the RQ. Quercetin and naringenin have a similar chemical structure (flavan backbone (2-phenylchroman)) and both inhibit PI3K in vitro ${ }^{(14,15)}$ as well as cytochrome $\mathrm{P} 450$ in vivo $\left((\mathrm{CYP} 1 \mathrm{~A} 2)^{(53)}\right)$. The functional group of quercetin (chromone moiety) directly blocks the ATP-binding site of $\mathrm{PI} 3 \mathrm{~K}^{(14)}$ and is thus able to reduce enzyme activity. The same inhibitory functional group can be found in naringenin and might also be able to reduce PI3K activity. These parameters strongly suggest that both naringenin and quercetin have a similar mode of action. Thus, it is plausible that quercetin impairs glucose tolerance and glucose utilisation via inhibition of hypothalamic insulin signalling. A reduction in insulin-induced pAkt in the ARC after quercetin treatment supports this idea. An acute central inhibition of insulin signalling by the flavonoids may be largely responsible for the observed effects on glucose metabolism as ICV naringenin is as effective as oral administration. However, we cannot exclude the fact that inhibition of PI3K activity in the periphery also contributes to impairment in whole body glucose metabolism. It has been described that flavonoids inhibit glucose uptake in adipocytes $^{(15,27)}$ and glucose transport by human intestinal cells $^{(54)}$. Controversially, however, naringenin was described to increase glucose uptake in muscle cells via a mechanism involving $5^{\prime}$ AMP-activated protein kinase ${ }^{(55)}$.

In addition to affecting glucose metabolism, oral naringenin and quercetin treatment led to a body weight gain and an increase in food intake. It is known that PI3K is involved in the regulation of energy homoeostasis. Activation of this pathway reduced body weight in mice ${ }^{(56)}$. Absence of the catalytic subunit p110 $\alpha$ or $\beta$ of PI3K in pro-opiomelanocortin neurons led to an increase in food intake and body weight $^{(57,58)}$. Quercetin reduces PI3K enzyme activity via inhibition of the ATP-binding site $e^{(14)}$, which is located on the catalytic subunit $\mathrm{p} 110^{(59)}$. The specific inhibition of this binding site by naringenin and quercetin might lead to the observed anabolic effect. However, the impairment in glucose metabolism after quercetin or naringenin treatment cannot be attributed to this observed anabolic effect as the intraperitoneal glucose tolerance test was performed immediately (15 min) after flavonoid application. We cannot exclude that chronic treatment with quercetin or naringenin might influence peripheral insulin sensitivity based on a possible chronic increase in body weight. However, recently we could show in Lep $^{\mathrm{ob} / \mathrm{ob}}$ mice that apparently not the body weight increase per se leads to impaired glucose homoeostasis, rather the absence of central leptin action appears to be the contributing factor to the development of glucose intolerance ${ }^{(21)}$.

The precise nature of how the polyphenols act on energy and glucose metabolism remains incompletely understood. Here, we could show that insulin- and basal IGFBP2 
$4 \mathrm{~h}$
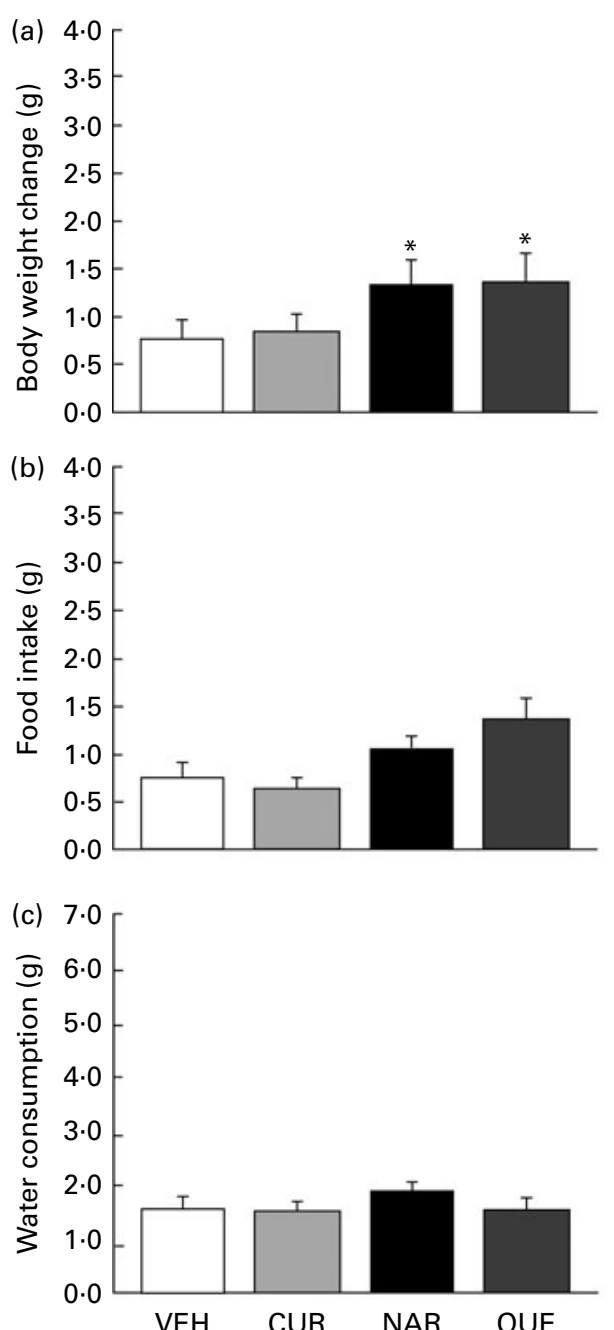

$24 \mathrm{~h}$

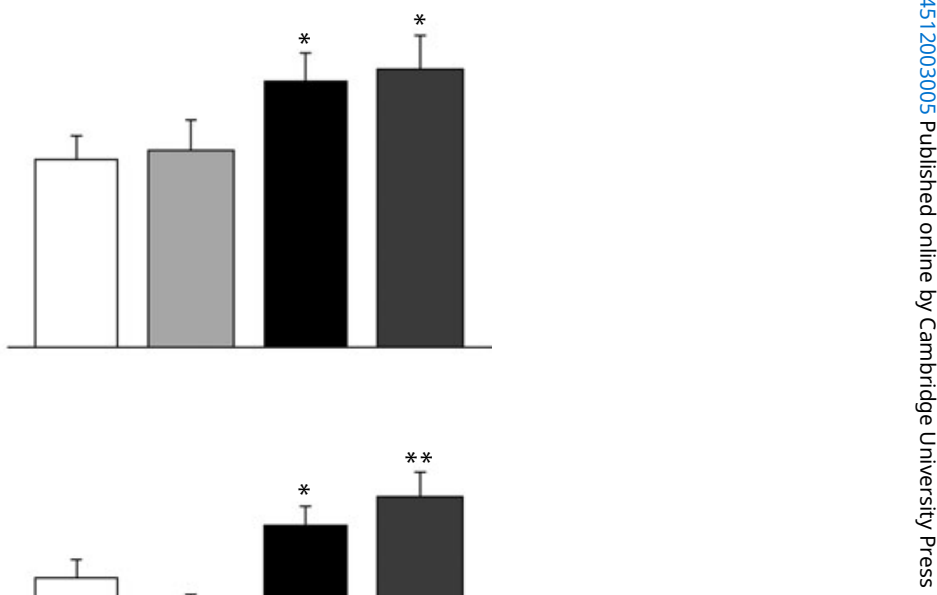

Fig. 7. Naringenin (NAR) and quercetin (QUE) significantly increased body weight gain and food intake of long day hamsters. (a) Body weight gain, (b) food intake and (c) water consumption 4 and $24 \mathrm{~h}$ after oral application of NAR, QUE, curcumin (CUR; $10 \mathrm{mg} / \mathrm{kg} ; n 9 \mathrm{hamsters} / \mathrm{group})$ or vehicle (VEH) (10\% ethanol-water; $n 8$ hamsters). Values are means with their standard errors. Mean values were significantly different: ${ }^{*} P<0.05,{ }^{\star \star} P<0 \cdot 01$.

concentrations did not change after polyphenol treatment. We measured IGFBP2 due to accumulating evidence showing that the growth hormone/insulin-like growth factor axis is involved in the regulation of glucose homoeostasis. It has been recently shown that the central effect of leptin to ameliorate glucose homoeostasis in leptin-deficient diabetic mice might be mediated via leptin-triggered release of IGFBP2 by the liver ${ }^{(24)}$. The present data suggest that it seems unlikely that the polyphenols also act on glucose metabolism via affecting IGFBP2 release. We cannot exclude, however, that basal IGFBP2 levels in blood might change after chronic polyphenol treatment.

The administered dietary dose of, e.g. naringenin, in the present experiments was equal to approximately $1 \mathrm{ml}$ grapefruit juice. Extrapolated to human dietary intake of naringenin, this treatment would approximately equal one glass of grapefruit juice $/ \mathrm{d}^{(60,61)}$. The average daily flavonoid intake in the USA was reported to be approximately $1 \mathrm{~g} /$ person $^{(62)}$.
This suggests that naringenin and quercetin are highly potent inhibitors of PI3K in vivo. Acute dietary consumption of grapefruits and green tea might lead to a similar plasma load, as observed in animals, and consequently might impair glucose metabolism. Whether chronic consumption of these nutrients might contribute to the development of type 2 diabetes remains a matter of debate. Future experiments involving chronic polyphenol treatment and other animal models that exhibit a profound phenotype of insulin resistance are required to solve this important issue.

\section{Acknowledgements}

The present study was funded by the German Ministry of Education and Research (reference no. 0315087, to A. T.). We appreciate statistical support by Dr L. M. Williams and G. Horgan at the Rowett Research Institute of Nutrition and Health. C. E. K. performed the in vivo experiments, analysed 
the data and wrote the manuscript. K. L. performed metabolic measurements with the expertise of G. H. D. S. and J. S. assisted by performing and analysing the immunohistochemistry. G. K. G. and S. S. performed in vitro experiments. G. K. G. was also involved in writing sections of the manuscript. N. H. reviewed/edited the manuscript. A. T. designed the study and reviewed/edited the manuscript. All authors approved the final version to be published and have no conflict of interest to declare.

\section{References}

1. Ross JA \& Kasum CM (2002) Dietary flavonoids: bioavailability, metabolic effects, and safety. Annu Rev Nutr 22, 19-34.

2. Nijveldt RJ, van NE, van Hoorn DE, et al. (2001) Flavonoids: a review of probable mechanisms of action and potential applications. Am J Clin Nutr 74, 418-425.

3. Aggarwal BB, Sundaram C, Malani N, et al. (2007) Curcumin: the Indian solid gold. Adv Exp Med Biol 595, 1-75.

4. Jagetia GC \& Aggarwal BB (2007) 'Spicing up' of the immune system by curcumin. J Clin Immunol 27, 19-35.

5. Justesen U, Knuthsen P \& Leth T (1998) Quantitative analysis of flavonols, flavones, and flavanones in fruits, vegetables and beverages by high-performance liquid chromatography with photo-diode array and mass spectrometric detection. J Chromatogr A 799, 101-110.

6. Del RD, Stewart AJ, Mullen W, et al. (2004) HPLC-MSn analysis of phenolic compounds and purine alkaloids in green and black tea. J Agric Food Chem 52, 2807-2815.

7. Wang HF \& Helliwell K (2001) Determination of flavonols in green and black tea leaves and green tea infusions by highperformance liquid chromatography. Food Res Int 34, 223-227.

8. Kannappan S \& Anuradha CV (2010) Naringenin enhances insulin-stimulated tyrosine phosphorylation and improves the cellular actions of insulin in a dietary model of metabolic syndrome. Eur J Nutr 49, 101-109.

9. Kobori M, Masumoto S, Akimoto Y, et al. (2009) Dietary quercetin alleviates diabetic symptoms and reduces streptozotocin-induced disturbance of hepatic gene expression in mice. Mol Nutr Food Res 53, 859-868.

10. Na LX, Zhang YL, Li Y, et al. (2011) Curcumin improves insulin resistance in skeletal muscle of rats. Nutr Metab Cardiovasc Dis 21, 526-533.

11. Ortiz-Andrade RR, Sanchez-Salgado JC, Navarrete-Vazquez G, et al. (2008) Antidiabetic and toxicological evaluations of naringenin in normoglycaemic and NIDDM rat models and its implications on extra-pancreatic glucose regulation. Diabetes Obes Metab 10, 1097-1104.

12. Bruning JC, Gautam D, Burks DJ, et al. (2000) Role of brain insulin receptor in control of body weight and reproduction. Science 289, 2122-2125.

13. Koch L, Wunderlich FT, Seibler J, et al. (2008) Central insulin action regulates peripheral glucose and fat metabolism in mice. J Clin Invest 118, 2132-2147.

14. Walker EH, Pacold ME, Perisic O, et al. (2000) Structural determinants of phosphoinositide 3-kinase inhibition by wortmannin, LY294002, quercetin, myricetin, and staurosporine. Mol Cell 6, 909-919.

15. Harmon AW \& Patel YM (2003) Naringenin inhibits phosphoinositide 3-kinase activity and glucose uptake in 3T3-L1 adipocytes. Biochem Biophys Res Commun 305, 229-234.

16. Kizhakkayil J, Thayyullathil F, Chathoth S, et al. (2010) Modulation of curcumin-induced Akt phosphorylation and apoptosis by PI3K inhibitor in MCF-7 cells. Biochem Biophys Res Commun 394, 476-481.

17. Okamoto H, Nakae J, Kitamura T, et al. (2004) Transgenic rescue of insulin receptor-deficient mice. J Clin Invest 114, 214-223.

18. Okamoto H, Obici S, Accili D, et al. (2005) Restoration of liver insulin signaling in Insr knockout mice fails to normalize hepatic insulin action. J Clin Invest 115, 1314-1322.

19. Mercer JG \& Tups A (2003) Neuropeptides and anticipatory changes in behaviour and physiology: seasonal body weight regulation in the Siberian hamster. Eur J Pharmacol 480, $43-50$.

20. Saha JK, Xia J, Grondin JM, et al. (2005) Acute hyperglycemia induced by ketamine/xylazine anesthesia in rats: mechanisms and implications for preclinical models. Exp Biol Med (Maywood) 230, 777-784.

21. Koch C, Augustine RA, Steger J, et al. (2010) Leptin rapidly improves glucose homeostasis in obese mice by increasing hypothalamic insulin sensitivity. $J$ Neurosci 30 , 16180-16187.

22. Tups A, Anderson GM, Rizwan M, et al. (2010) Both p110alpha and p110beta isoforms of phosphatidylinositol 3-OH-kinase are required for insulin signalling in the hypothalamus. J Neuroendocrinol 22, 534-542.

23. Heldmaier G \& Ruf T (1992) Body temperature and metabolic rate during natural hypothermia in endotherms. J Comp Physiol B 162, 696-706.

24. Hedbacker K, Birsoy K, Wysocki RW, et al. (2010) Antidiabetic effects of IGFBP2, a leptin-regulated gene. Cell Metab 11, 11-22.

25. Heldmaier G, Klingenspor M, Werneyer M, et al. (1999) Metabolic adjustments during daily torpor in the Djungarian hamster. Am J Physiol 276, E896-E906.

26. Harmon AW \& Patel YM (2004) Naringenin inhibits glucose uptake in MCF-7 breast cancer cells: a mechanism for impaired cellular proliferation. Breast Cancer Res Treat $\mathbf{8 5}$, 103-110.

27. Nomura M, Takahashi T, Nagata N, et al. (2008) Inhibitory mechanisms of flavonoids on insulin-stimulated glucose uptake in MC3T3-G2/PA6 adipose cells. Biol Pharm Bull 31, 1403-1409.

28. Strobel P, Allard C, Perez-Acle T, et al. (2005) Myricetin, quercetin and catechin-gallate inhibit glucose uptake in isolated rat adipocytes. Biochem J 386, 471-478.

29. Cheatham B, Vlahos CJ, Cheatham L, et al. (1994) Phosphatidylinositol 3-kinase activation is required for insulin stimulation of pp70 S6 kinase, DNA synthesis, and glucose transporter translocation. Mol Cell Biol 14, 4902-4911.

30. Clarke JF, Young PW, Yonezawa K, et al. (1994) Inhibition of the translocation of GLUT1 and GLUT4 in 3T3-L1 cells by the phosphatidylinositol 3-kinase inhibitor, wortmannin. Biochem J 300, 631-635.

31. Okada T, Kawano Y, Sakakibara T, et al. (1994) Essential role of phosphatidylinositol 3-kinase in insulin-induced glucose transport and antilipolysis in rat adipocytes. Studies with a selective inhibitor wortmannin. J Biol Chem 269, 3568-3573.

32. Kannappan S \& Anuradha CV (2009) Insulin sensitizing actions of fenugreek seed polyphenols, quercetin \& metformin in a rat model. Indian J Med Res 129, 401-408.

33. Mulvihill EE, Allister EM, Sutherland BG, et al. (2009) Naringenin prevents dyslipidemia, apolipoprotein B overproduction, and hyperinsulinemia in LDL receptor-null mice with diet-induced insulin resistance. Diabetes $\mathbf{5 8}$, 2198-2210.

34. Woo JH, Kim YH, Choi YJ, et al. (2003) Molecular mechanisms of curcumin-induced cytotoxicity: induction of 
apoptosis through generation of reactive oxygen species, down-regulation of $\mathrm{Bcl}-\mathrm{XL}$ and IAP, the release of cytochrome $c$ and inhibition of Akt. Carcinogenesis 24, 1199-1208.

35. Yu S, Shen G, Khor TO, et al. (2008) Curcumin inhibits Akt/ mammalian target of rapamycin signaling through protein phosphatase-dependent mechanism. Mol Cancer Ther 7, 2609-2620

36. Siwak DR, Shishodia S, Aggarwal BB, et al. (2005) Curcumininduced antiproliferative and proapoptotic effects in melanoma cells are associated with suppression of IkappaB kinase and nuclear factor kappaB activity and are independent of the B-Raf/mitogen-activated/extracellular signalregulated protein kinase pathway and the Akt pathway. Cancer 104, 879-890.

37. Nishiyama T, Mae T, Kishida H, et al. (2005) Curcuminoids and sesquiterpenoids in turmeric (Curcuma longa L.) suppress an increase in blood glucose level in type 2 diabetic KK-Ay mice. J Agric Food Chem 53, 959-963.

38. Mercer JG, Hoggard N, Williams LM, et al. (1996) Localization of leptin receptor mRNA and the long form splice variant $(\mathrm{Ob}-\mathrm{Rb})$ in mouse hypothalamus and adjacent brain regions by in situ hybridization. FEBS Lett 387, 113-116.

39. Niswender KD, Morrison CD, Clegg DJ, et al. (2003) Insulin activation of phosphatidylinositol 3-kinase in the hypothalamic arcuate nucleus: a key mediator of insulin-induced anorexia. Diabetes 52, 227-231.

40. Sanderson TH, Kumar R, Murariu-Dobrin AC, et al. (2009) Insulin activates the PI3K-Akt survival pathway in vulnerable neurons following global brain ischemia. Neurol Res 31, 947-958.

41. Unger JW, Livingston JN \& Moss AM (1991) Insulin receptors in the central nervous system: localization, signalling mechanisms and functional aspects. Prog Neurobiol 36, 343-362.

42. Werther GA, Hogg A, Oldfield BJ, et al. (1987) Localization and characterization of insulin receptors in rat brain and pituitary gland using in vitro autoradiography and computerized densitometry. Endocrinology 121, 1562-1570.

43. Kanoski SE, Hayes MR, Greenwald HS, et al. (2011) Hippocampal leptin signaling reduces food intake and modulates food-related memory processing. Neuropsychopharmacology 36, 1859-1870.

44. Satoh N, Ogawa Y, Katsuura G, et al. (1997) The arcuate nucleus as a primary site of satiety effect of leptin in rats. Neurosci Lett 224, 149-152.

45. Perkins S, Verschoyle RD, Hill K, et al. (2002) Chemopreventive efficacy and pharmacokinetics of curcumin in the $\mathrm{min} /+$ mouse, a model of familial adenomatous polyposis. Cancer Epidemiol Biomarkers Prev 11, 535-540.

46. Sharma RA, Ireson CR, Verschoyle RD, et al. (2001) Effects of dietary curcumin on glutathione $S$-transferase and malondialdehyde-DNA adducts in rat liver and colon mucosa: relationship with drug levels. Clin Cancer Res 7, 1452-1458.

47. Felgines C, Texier O, Morand C, et al. (2000) Bioavailability of the flavanone naringenin and its glycosides in rats. $A m J$ Physiol Gastrointest Liver Physiol 279, G1148-G1154.
48. Youdim KA, Dobbie MS, Kuhnle G, et al. (2003) Interaction between flavonoids and the blood-brain barrier: in vitro studies. J Neurochem 85, 180-192.

49. Youdim KA, Qaiser MZ, Begley DJ, et al. (2004) Flavonoid permeability across an in situ model of the blood-brain barrier. Free Radic Biol Med 36, 592-604.

50. Youdim KA, Shukitt-Hale B \& Joseph JA (2004) Flavonoids and the brain: interactions at the blood-brain barrier and their physiological effects on the central nervous system. Free Radic Biol Med 37, 1683-1693.

51. El Mohsen MA, Marks J, Kuhnle G, et al. (2004) The differential tissue distribution of the citrus flavanone naringenin following gastric instillation. Free Radic Res 38, 1329-1340.

52. Sabarinathan D \& Vanisree AJ (2010) Naringenin, a flavanone alters the tumorigenic features of $\mathrm{C} 6$ glioma cells. Biomed Pharmacother (Epublication ahead of print version 20 December 2010).

53. Chen Y, Xiao P, Ou-Yang DS, et al. (2009) Simultaneous action of the flavonoid quercetin on cytochrome P450 (CYP) 1A2, CYP2A6, $N$-acetyltransferase and xanthine oxidase activity in healthy volunteers. Clin Exp Pharmacol Physiol 36, 828-833.

54. Manzano S \& Williamson G (2010) Polyphenols and phenolic acids from strawberry and apple decrease glucose uptake and transport by human intestinal Caco-2 cells. Mol Nutr Food Res 54, 1773-1780.

55. Zygmunt K, Faubert B, MacNeil J, et al. (2010) Naringenin, a citrus flavonoid, increases muscle cell glucose uptake via AMPK. Biochem Biophys Res Commun 398, 178-183.

56. Plum L, Rother E, Munzberg H, et al. (2007) Enhanced leptinstimulated Pi3k activation in the CNS promotes white adipose tissue transdifferentiation. Cell Metab 6, 431-445.

57. Al-Qassab H, Smith MA, Irvine EE, et al. (2009) Dominant role of the p110beta isoform of PI3K over p110alpha in energy homeostasis regulation by POMC and AgRP neurons. Cell Metab 10, 343-354.

58. Hill JW, Elias CF, Fukuda M, et al. (2010) Direct insulin and leptin action on pro-opiomelanocortin neurons is required for normal glucose homeostasis and fertility. Cell Metab 11, 286-297.

59. Wymann MP \& Pirola L (1998) Structure and function of phosphoinositide 3-kinases. Biochim Biophys Acta 1436 127-150.

60. Erlund I, Meririnne E, Alfthan G, et al. (2001) Plasma kinetics and urinary excretion of the flavanones naringenin and hesperetin in humans after ingestion of orange juice and grapefruit juice. J Nutr 131, 235-241.

61. Ho PC, Saville DJ, Coville PF, et al. (2000) Content of CYP3A4 inhibitors, naringin, naringenin and bergapten in grapefruit and grapefruit juice products. Pharm Acta Helv 74, 379-385.

62. Kuhnau J (1976) The flavonoids. A class of semi-essential food components: their role in human nutrition. World Rev Nutr Diet 24, 117-191. 